\title{
Alan Lawrence OBE
}

\section{Derek Richards}

Editor, Evidence-based Dentistry
In early September, Alan Lawrence, our founding editor, sadly passed away after a 3-year battle against cancer.

I had the privilege of working with Alan for the last 15 years, developing evidencebased dentistry here in the UK. In August 1994, I began my specialist dental public health training with him and within months we had met with Sir Muir Gray (Muir was knighted in 2005 for services to the UK National Health Service) and David Sackett. Muir had just brought David Sackett over from Canada to establish the Centre for Evidence-based Medicine. The energy and enthusiasm of these individuals was such that, before the end of the year, Alan had pulled together a workshop on evidence-based dentistry, which was held at Templeton College in Oxford. Alan's persuasiveness secured the attendance of key representatives from the Department of Health, Royal Colleges and Postgraduate Deaneries and a broad range of dental representation.

Two action points from the workshops were to develop a centre and a journal. Within 6 months Alan had established the Centre for Evidence-based Dentistry, and shortly afterwards he and I had our first website in operation and published our first paper on evidence-based dentistry. ${ }^{1}$ The website and centre was initially hosted at the then Institute of Health Sciences in Oxford, but the website has since become freestand- ing (www.cebd.org). Alan became the first Chairman of the centre and was always an enthusiastic supporter and advocate of the evidence-based approach.

Within the first 2 years of the centre's existence we had, between us, provided training in the evidence-based approach to around 300 dental personnel. Alan, who was president of the British Association for Community Dentistry (BASCD) in 1997, after many years service as the BASCD secretary, took evidence-based healthcare as the theme for his presidential year. The event was a resounding success, mixing lectures with hands-on workshops in the evidence-based approach.

Towards the end of 1998, after a long period of negotiation with Mike Grace, the then editor of the British Dental Journal, and its publisher, Alan managed to negotiate the production of the very first Evidence-based Dentistry journal. This appeared as a supplement to the British Dental Journal in November 1998. Alan edited the early issues of the journal until he passed the baton to me: we still use many of the processes that he established, to this day. The journal has been almost completely compiled electronically since its establishment, driven by Alan's love of new technology and support of the internet for communicating.

Alan retired early from his post as Consultant in Dental Public Health in mid-1998 but that did not reduce his involvement in evidence-based dentistry or dental matters. He was a life vice-president of the Christian Dental Fellowship and lectured regularly on Health and Safety, Clinical Governance and Clinical Photography. He was also the Department of Health's Retaining and Returning Adviser for UK Dentists working overseas on the Keeping in Touch Scheme from 2001 to 2006. In the 1999 New Years Honours list, Alan was awarded an OBE for services to community dentistry. Our thoughts go to Alan's wife Judith and his family at this sad time.

1 Richards D, Lawrence A. Evidence based dentistry. Br Dent / 1995; 179: 270-273.

Evidence-Based Dentistry (2009) 10, 66. doi: $10.1038 /$ sj.ebd. 6400660

\section{Erratum}

Jin $L$. Is oral irrigation beneficial to gingival health as an adjunct to toothbrushing? Evid based Dent 2009; 10: 40-41.

There is a typographical error in the above article. The first line of the commentary should read, "It has been estimated that at least $10^{14}$ species of commensal microbes reside", not "It has been estimated that at least 1014 species of commensal microbes" as printed. 